\title{
In vitro evaluation of some isolated bacteria against the plant parasite nematode Meloidogyne incognita
}

\author{
Gaziea Mohamed Soliman', Hoda Hussein Ameen', Shadia Mohamed Abdel-Aziz² \\ and Ghada M. El-Sayed ${ }^{2 *}$
}

\begin{abstract}
Background: Microbial cultures are extensively used as environment friendly ways for biological control of parasitic pests, including the root-knot nematodes, alternative to the use of chemical nematicides. The present study was conducted to isolate some lytic rhizobacteria and examine their nematicidal activity against Meloidogyne incognita $J_{2}$ mortality and egg hatching in in vitro test.

Results: Lytic Rhizobacteria were isolated from soil samples adhering to tomato plant roots from different localities at Giza governorate, Egypt. Six bacterial isolates, exhibited high efficacy against root-knot nematodes, were identified based on the analysis of the $16 \mathrm{~S}$ rRNA gene sequence as Pseudomonas aeruginosa, Paenibacillus polymyxa, Lysinibacillus sphaericus, Bacillus cereus, Bacillus subtilis, and Achromobacter xylosoxidans. These strains showed high production of chitinase, chitosanase, and protease using colloidal chitin and soluble chitosan as carbon sources. Two strains, Paenibacillus polymyxa and Bacillus subtilis, produced the highest levels of chitinase in the media. Except for Pseudomonas aeruginosa, all the bacterial strains produced high levels of chitosanase.
\end{abstract}

Conclusion: The results revealed that high amounts of protease were, however, secreted by Pseudomonas aeruginosa as compared to the other strains. In in vitro tests, all the bacterial culture filtrates potentially displayed nematicidal effect in $M$. incognita egg hatching and an obvious increase in $J_{2}$ mortality as compared to control. Paenibacillus polymyxa caused 100\% juvenile mortality followed by Bacillus subtilis $97.25 \%$, Bacillus cereus $94 \%$, Achromobacter xylosoxidans 93\%, Lysinibacillus sphaericus 92\%, and Pseudomonas aeruginosa $84.29 \%$ after $48 \mathrm{~h}$ of exposure, as compared to control.

Keywords: Rhizobacteria, $16 \mathrm{~S}$ rRNA, Lytic enzymes, Biocontrol, Meloidogyne incognita

\section{Introduction}

The word sustainable agriculture has been resounded among international organizations over the past decades. Sustainable agriculture has become one of the fundamental needs to ensure food security worldwide (Glick 2012; Gupta et al. 2015). Meloidogyne spp., the most extensively studied nematode genera attack plants, have been economically reported as root-knot nematodes. The potential negative impacts of synthetic nematicides have created the need to discover alternative safe and ecofriendly control methods.

\footnotetext{
*Correspondence: Ghada.khalefa@yahoo.com

${ }^{2}$ Genetic Engineering and Biotechnology Division, Microbial Genetic

Department, National Research Centre, Giza, Egypt

Full list of author information is available at the end of the article
}

Biological control using plant-growth-promoting rhizobacteria (PGPR) is a promising tool and safe alternative approach for controlling plant-parasitic nematodes (Lee and Kim 2016; Rika et al. 2017; Priyank et al. 2018; Sidhu 2018). Lytic strains secrete protease and chitinase, which have been extensively studied. The basic rationale behind their use is that, the biochemical composition of nematode structure includes collagens and lipids during the mobile stages, as well as chitin, protein, and lipids in the sedentary stages for tylenchoid nematodes such as Meloidogyne spp. The egg shell of root-knot nematode is composed of three main layers: (a) the outer vitelline layer that support the structural uniformity of eggs (Wharton 1980); (b) the middle chitinous layer of the egg shell which contains chitin fibrils 
embedded in a protein matrix (Lee et al. 2015), and (c) the inner lipid layer which maintain the impermeability of the shell (Bird and McClure 1976). The chitinous layer provides protection for the lipid layer and structural strength.

Protease and chitinase cause significant damage to the cuticle of nematodes and can directly affect their infective stages. Extracellular crude chitinases, proteases, and gelatinases (gelatinolytic proteins) produced by bacteria have been reported to kill nematodes, destroy their larvae, damage the egg shell, and reduce egg hatching (Spiegel et al. 1991; Jung et al. 2002; Huang et al. 2005; Niu et al. 2006; Tian et al. 2007). Protease and gelatinase (gelatinolytic proteins) produced by bacteria induced death of $\mathrm{J}_{2}$ of root-knot nematodes (Niu et al. 2006). Moreover, the nematicidal effect of chitinases on rootknot nematodes egg hatch and $\mathrm{J}_{2}$ mortality has been investigated. Incubation of Meloidogyne hapla eggs with chitinase purified from Serratia marcescens and Streptomyces griseus had led to the formation of eggs with aberrant shape and large vacuoles in the chitinous layer and to a split in the vitelline layer which finally result in a loss of egg integrity (Mercer et al. 1992). Purified chitinase from Lysobacter capsici effectively disrupted the egg shell of Meloidogyne spp. and significantly reduced hatching (Lee et al. 2015). The present study aims to (a) isolate and identify some lytic bacterial strains from soil adhering to tomato plant roots, (b) evaluate their production of chitinase, chitosanase and protease, and $(c)$ investigate the nematicidal potential of the isolated strains against Meloidogyne incognita and egg hatchability under in vitro conditions.

\section{Materials and methods}

\section{Isolation of bacterial strains}

The sampling was carried when the prevailing atmospheric temperature was $26{ }^{\circ} \mathrm{C}$. Six soil samples were randomly selected from tomato fields from Giza governorate, Egypt. Plants were uprooted carefully, the excess of agriculture soil around the roots was removed by gentle shaking, and the adhering soil represented the composite samples. The collected samples were placed in sterilized plastic bags and transferred to the laboratory under controlled temperature conditions. The soil sample were serially diluted in saline $(0.85 \%, \mathrm{NaCl} \mathrm{w} / \mathrm{v})$ spread and plated in triplicate on Luria-Bertani (LB) agar medium (Atlas 1995), followed by incubation at $30{ }^{\circ} \mathrm{C}$ for $48 \mathrm{~h}$. Bacterial isolates were maintained on the respective slants.

\section{Extraction of genomic DNA from bacterial isolates}

Single colony of each bacterial isolate was cultured in conical flasks (Pyrex, USA) containing $20 \mathrm{ml}$ LB medium by shaking in a rotary shaker at $180 \mathrm{rpm}$ for $18 \mathrm{~h}$ followed by centrifugation of cultures at 13,000 rpm for
5 min at $4{ }^{\circ} \mathrm{C}$. The pellets were subjected to genomic DNA extraction using the (QIAamp DNA Mini Kit, QIAGEN, Germany). The extracted DNA was used as a template for PCR to amplify $16 \mathrm{~S}$ rDNA.

\section{Molecular identification of isolated bacterial strains by PCR amplification and sequencing of 16SrDNA}

Bacterial 16S rDNA gene was amplified by PCR using the universal primers; forward primer sequence (5' AGAGTTTGATCCTGGCTCAG3') and reverse primer sequence (5'CTACGGCTACCTTGTTACGA3') thereby producing an amplicon of $\sim 1500 \mathrm{bp}$. In this reaction, amplification was carried out in $50 \mu$ l reactions using a PCR master mix kit (Qiagen, Germany) according to the manufacturer's instructions using a GeneAmp PCR System 2400 Thermal cycler (Perkin-Elmer). The following program was used: $94{ }^{\circ} \mathrm{C}$ for $3 \mathrm{~min}$ as the initial denaturation step, followed by 35 cycles of denaturation at $94{ }^{\circ} \mathrm{C}$ for $30 \mathrm{~s}$, annealing at $55{ }^{\circ} \mathrm{C}$ for 1 -min extension at $72{ }^{\circ} \mathrm{C}$ for $2 \mathrm{~min}$, with a final extension at $72{ }^{\circ} \mathrm{C}$ for $10 \mathrm{~min}$ (Elsayed et al. 2018). PCR products were purified by QIAquick Gel Extraction Kit (Qiagen, Germany) following the protocol provided by the supplier and then resolved by electrophoresis on $1 \%$ agarose gels. Nucleotide sequence was determined using the same Primers with the dideoxy-chain termination method using the PRISM Ready Reaction Dye terminator/primer cycle sequencing kit (Perkin-Elmer Corp., Norwalk, CN, USA). The obtained sequences were analyzed for similarities to other known sequences found in the GenBank database using BLAST program of the NCBI database.

\section{Detection of enzymes}

Secretion of enzymes, chitinase and chitosanase by six bacterial strains, were evaluated in media containing colloidal chitin and soluble chitosan (30\% acetylated), respectively. Chitinase activity was assayed by measuring the release of reducing sugars from colloidal chitin (Monreal and Reese 1969). Chitosanase activity was detected as described by Fenton and Eveleigh (1981) using soluble chitosan (30\% acetylated) at a concentration of $1 \%$ concentration. The standard assay mixture and amount of reducing sugars were performed as described previously (Abdel-Aziz et al. 2008), according to the method of Somogyi (Somogyi 1952). Release of reducing sugars as detected at A540 was converted to molar quantity using a standard calibration curve with $\mathrm{N}$ acetyl-D-glucosamine and glucosamine for chitinase and chitosanase, respectively (Somogyi 1952). One unit of enzyme activity was defined as the amount of enzyme that released $1 \mu \mathrm{mol}$ of reducing sugars per minute. Protease activity was determined as described previously (Abdel-Salam et al. 2018). 


\section{Preparation of substrates}

Colloidal chitin was prepared using flaked chitin (Sigma Chemicals Company, USA) by the method of Monreal and Reese (1969). Chitin flakes were added to $10 \mathrm{~N} \mathrm{HCl}$ and kept overnight at $4{ }^{\circ} \mathrm{C}$. The suspension was added to a $50 \%$ cold ethanol with stirring and then kept overnight at $4{ }^{\circ} \mathrm{C}$. The precipitate was collected by centrifugation at $5000 \times g$ for $20 \mathrm{~min}$, washed with sterile distilled water until the colloidal chitin became neutral ( $\mathrm{pH} 7.0)$, and stored at $4{ }^{\circ} \mathrm{C}$ until further use. Chitosan solution was prepared by the method of Fenton and Eveleigh (1981).

\section{In vitro nematicidal activity}

The nematicidal activity was assayed in in vitro by the percentage inhibition of egg hatch and $\mathrm{J}_{2}$ mortality of root-knot nematode $M$. incognita.

\section{Preparation of bacterial culture filtrates}

After the incubation period, bacterial cultures were centrifuged at $5000 \mathrm{rpm}$ for $15 \mathrm{~min}$ and the supernatant solution was passed through a $0.22 \mu \mathrm{m}$ in diameter nitrocellulose filter to prepare sterile culture filtrates for the bioassay tests.

\section{Preparation of nematode inoculum}

Extraction of Meloidogyne incognita eggs and $\mathrm{J}_{2}:$ M. incognita was obtained from pure cultures maintained on roots of the eggplant, Solanum melongena. The infected roots were removed from soil, washed with tap water, and cut into approximately $1-2 \mathrm{~cm}$ pieces. The eggs were collected according to the method of Hussey and Barker (1973), and the extracted eggs were used immediately for egg hatching ability test, or incubation in egg hatching plastic cups at the laboratory temperature ( 25 $\pm 3{ }^{\circ} \mathrm{C}$ ) for $72 \mathrm{~h}$ to provide nematode $\mathrm{J}_{2}$ for juvenile's mortality test. To estimate the inoculum density, the egg suspension was poured into a measuring cylinder. Numbering of eggs was estimated in five aliquots of $1 \mathrm{ml}$ in a Hawksley counting slide under a light microscope, and their means were calculated. Based on the total volume of suspension, total number of eggs was estimated. For concentrating the eggs suspension, it was left to settle down for several hours; afterwards, the extra water was decanted off leaving the bottom undisturbed and the same was done with $\mathrm{J}_{2}$ to estimate the inoculum density.

\section{Effect of bacterial culture filtrate on $M$. incognita egg hatching}

This test was performed to ascertain the direct effect of the bacterial filtrate on M. incognita egg hatch. Two milliliters of eggs suspended in distilled water containing approximately 100 eggs \pm 10 was placed in Petri dishes, plus $2 \mathrm{ml}$ of the bacterial culture filtrates containing $2 \times$ $10^{7} \mathrm{CFU} / \mathrm{ml}$ of each bacterial strain, separately. Plain water in Petri dishes supplied with nematode suspension was served as control. Each treatment was replicated five times. The Petri dishes were kept at room temperature $\left(30{ }^{\circ} \mathrm{C}\right)$. Hatching eggs were examined, after 7 days exposure; the number of hatched eggs was counted under a stereomicroscope. At the end of exposure, all treatments were transferred to the distilled water for $24 \mathrm{~h}$, to be ensured that no recovery will occur. Relative hatching and Hatching inhibition (\%) were calculated as follows:

Relative hatching $\%=$ Number of hatched $\mathrm{J}_{2}$ in each treatment $\div$ Number of hatched $J_{2}$ in water $\times 100$.

Hatching inhibition \% = $100-$ Relative hatching (\%).

\section{Effect of bacterial culture filtrate on $M$. incognita $J_{2}$ mortality}

For mortality test, $2 \mathrm{ml}$ of freshly hatched second-stage juveniles of $M$. incognita in sterile distilled water as previously described containing $50 \pm 5$ larvae $/ \mathrm{ml}$ was placed in each Petri dish and $2 \mathrm{ml}$ of culture filtrate from each bacterial strain containing $2 \times 10^{7} \mathrm{CFU} / \mathrm{ml}$ was added separately. Petri dish with nematodes and without culture filtrate served as control. There were five replicates from each treatment. The numbers of juveniles killed after $48 \mathrm{~h}$ were recorded using a stereoscope. After exposure periods, juveniles were washed using distilled water then transferred to clean Petri dishes for $24 \mathrm{~h}$ to ensure that no recovery will be occurred. The percentage of nematode mortality was calculated according to Abbott's formula (Abbot 1925).

\section{Data analysis}

Data obtained from laboratory bioassays for hatched eggs and mortality (\%) was subjected to analysis of variance (ANOVA) and means compared according to Duncan's multiple range test (Duncan 1955).

\section{Results}

Molecular identification of isolated bacterial strains

In the present study, six bacterial isolates were designated as CH7GES, CH6GES, CH4GES, 4PLGES, SGES, and 19GES. These isolates were identified by analysis of the sequence similarity of $16 \mathrm{~S}$ rDNA gene sequence with that on Genbank database as Pseudomonas aeruginosa, Paenibacillus polymyxa, Lysinibacillus sphaericus, Bacillus cereus, Bacillus subtilis, and Achromobacter xylosoxidans, respectively. The DNA sequence for the $16 \mathrm{~s}$ rDNA of these strains has been deposited in the GenBank database with accession numbers shown in Table 1. 
Table 1 The bacterial strains and their accession numbers in Genbank data base

\begin{tabular}{ll}
\hline Bacterial strains & Accession no. \\
\hline Pseudomonas aeruginosa CH7GES & LC215048.1 \\
Paenibacillus polymyxa CH6GES & LC215049.1 \\
Lysinibacillus sphaericus CH4GES & LC215050.1 \\
Bacillus cereus 4PLGES & LC215052.1 \\
Bacillus subtilis SGES & LC215051.1 \\
Achromobacter xylosoxidans 19GES & LC214968.1 \\
\hline
\end{tabular}

\section{Ability of the identified bacterial strains for enzymes secretion}

Ability of the six bacterial strains for secretion of lytic enzymes was measured. Results showed variation in secretion among the different isolates. Paenibacillus polymyxa and Bacillus subtilis showed the highest chitinase activity (100\%), followed by Bacillus cereus 98\%, Lysinibacillus sphaericus 97\%, P. aeruginosa 95\%, and Achromobacter xylosoxidans 92\% (Fig. 1). On other hand, all bacterial strains exhibited similar high chitosanase activities except for $P$. aeruginosa which showed the highest activity of protease (100\%), followed by Paenibacillus polymyxa and Lysinibacillus sphaericus produced (95\%), Achromobacter xylosoxidans (94\%), Bacillus cereus, and Bacillus cereus (90\%).

\section{Nematicidal potential of the isolated bacterial strains Effect on hatchability of $M$. incognita eggs}

The six culture filtrates exhibited significant reduction in M. incognita eggs hatching as compared to control. The percentages of inhibition are ranged from 77.97 to $62.96 \%$. Bacillus subtilis $77.97 \%$ caused the greatest inhibitory effect followed by Paenibacillus polymyxa $77.14 \%$, Achromobacter xylosoxidans 73.66\%, Bacillus cereus $70.06 \%$, Lysinibacillus sphaericus $65 \%$, and P. aeruginosa $62.96 \%$, after 7 days of exposure as compared to control, Table 2. The morphological changes of eggs and juveniles were observed under a stereomicroscope, and the abnormal developments are represented in Fig. 2. As shown, normal juvenile and normal egg are observed in distilled water, control (Fig. 2a, see arrows). However, abnormal development stages are occurred, deforming of eggshell (Fig. 2b, c, e). Some eggshells appeared to be destroyed and accompanied with abnormal hatching (Fig. 2d, arrow). Arrow in Fig. 2f reveals some eggs appeared to show many vacuoles.

\section{Effect on $M$. incognita $J_{2}$ mortality}

The identified bacterial strains were examined for their nematicidal activities via the effect of lytic enzymes in in vitro tests. Obtained results, after $48 \mathrm{~h}$ of exposure, revealed that all culture filtrates cause mortality (significant $p<0.05$ ) in $M$. incognita $\mathrm{J}_{2}$ as compared to control. The percentage of mortality ranged between 100 and 84.29\%. Paenibacillus polymyxa exhibited the highest percentage (100\%) mortality followed by Bacillus subtilis 97.25\%, Bacillus cereus 94\%, Achromobacter xylosoxidans 93\%, Lysinibacillus sphaericus 92\%, and P. aeruginosa $84.29 \%$ as compared to control (Table 3). The highest percentage of mortality showed by Paenibacillus polymyxa and Bacillus subtilis culture filtrates are in accordance with their potential secretion of enzymes as represented in Fig. 1.

\section{Discussion}

The root-knot nematodes, Meloidogyne spp., are recognized as the most important group of plant-parasitic nematodes occurring worldwide (Moens and Perry 2009). When grown around plant roots, parasitic nematodes establish feeding sites by inducting specific developmental pathways to suppress plant defense (Gheysen and Mitchum 2018). This interface between nematode developmental pathways and plant defense results in a complex pattern, so that it is difficult to induce the specific roles of different plant hormones and enzymes that

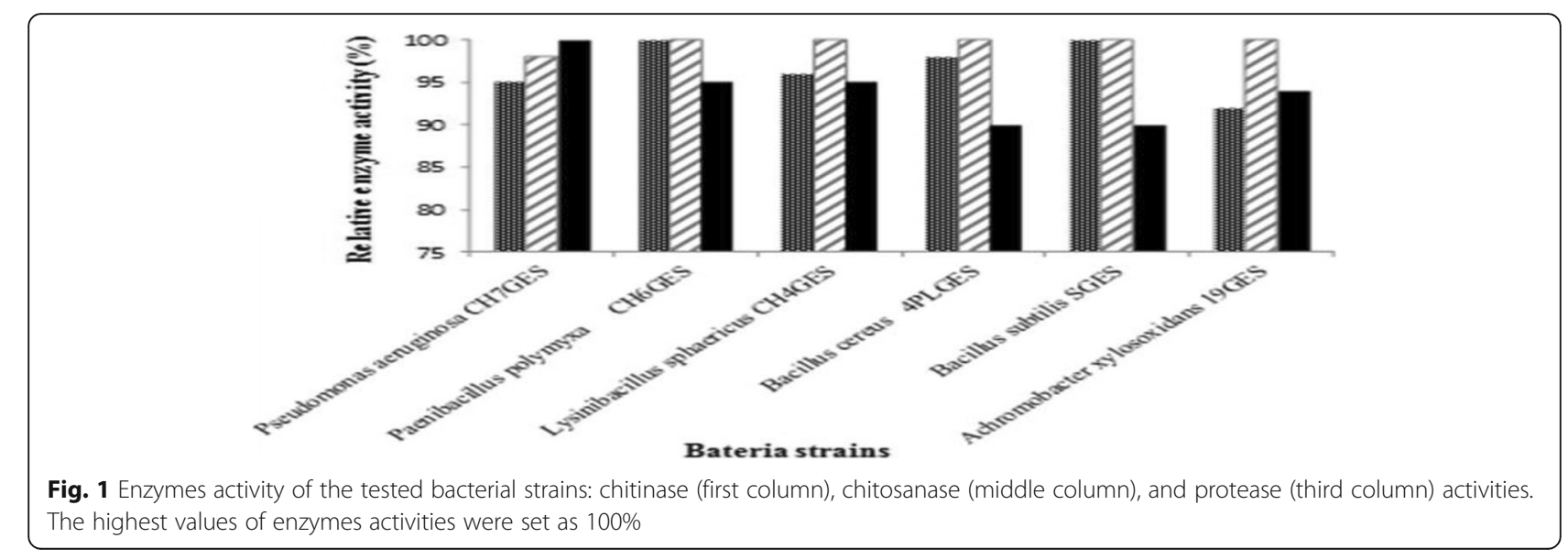


Table 2 Inhibition activity of the culture filtrates of the isolated bacterial strains on Meloidogyne incognita eggs after 7 days of exposure

\begin{tabular}{|c|c|c|c|}
\hline Bacterial isolates & No. of hatched eggs* & Relative hatching \%• & Hatching inhibition \%•• \\
\hline Control (water only) & $98.00 \mathrm{a}$ & 98 & 0.00 \\
\hline Pseudomonas aeruginosa CH7GES & $36.50 \mathrm{~b}$ & 37.04 & 62.96 \\
\hline Paenibacillus polymyxa CH6GES & $22.25 f$ & 22.86 & 77.14 \\
\hline Lysinibacillus sphaericus CH4GES & $34.00 \mathrm{c}$ & 35.00 & 65.00 \\
\hline Bacillus cereus $\mathrm{CH} 4 \mathrm{GES}$ & $29.50 d$ & 29.94 & 70.06 \\
\hline Bacillus subtilis SGES & $21.30 f$ & 22.03 & 77.97 \\
\hline Achromobacter xylosoxidans 19GES & $25.50 \mathrm{e}$ & 26.34 & 26.34 \\
\hline
\end{tabular}

*Means followed by the same letter(s) are not significantly different according to Duncan's Multiple Range Test. Data are averages of 5 replicates

-Relative hatching and $\bullet \bullet$ hatching inhibition (\%) are calculated as mentioned in M\&M. Data are averages of five replicates

act as growth stimulators (Gheysen and Mitchum 2018). Evolution of nematodes as plant parasites occurred several times, resulting in diverse interaction modes with the plant (Smant et al. 2018). One of the most promising alternative control methods to chemical nematicides is the application of antagonistic microorganisms especially those that produce lytic enzymes (El-Alfy and Schlenk 2002; Ashoub and Amara 2010).

The role of chitinase and other lytic enzymes in nematode biocontrol has intensively investigated. In the present study, all the isolated strains showed chitinase, chitosanase, and protease activities, effectively inhibited egg hatching, and obviously altered the eggshell structures. Moreover, eggs treated with the produced chitinase displayed large and more vacuoles in the chitin layer and increasing the mortality percentage of $M$. incognita $\mathrm{J}_{2}$ in in vitro tests. These results are in accordance with those reported by Mercer et al. (1992). In addition, maximum chitinase production was secreted by $P$. polymyxa and B. subtilis which resulted in high $\mathrm{J}_{2}$ mortality and egg hatching inhibition of $M$. incognita. In this context, Sohrabi et al. (2018) found that the bacterial strains $P$. polymyxa and B. subtilis significantly reduced the $\mathrm{J}_{2}$ population of Meloidogyne javanica. Batool et al. (2013) have reported that the strain P. aeruginosa caused more than $90 \%$ mortality in in vitro tests, performed with $M$. javanica, due to the high secretion of chitinase. Cetintas et al. (2018) reported that, among 15 studied bacterial strains, the strains Paenibacillus castaneae and Mycobacterium immunogenum are found to be best biocontrol agents for management of the nematode Meloidogyne incognita.

Proteases and chitinases play an important role in degradation of the nematode cuticle and serve as nematicidal factors for biocontrol of nematode populations. Rhizobacteria secrete proteases and chitinases for suppression of plant pathogenic nematodes by several mechanisms. $P$. aeruginosa affect nematode activity by
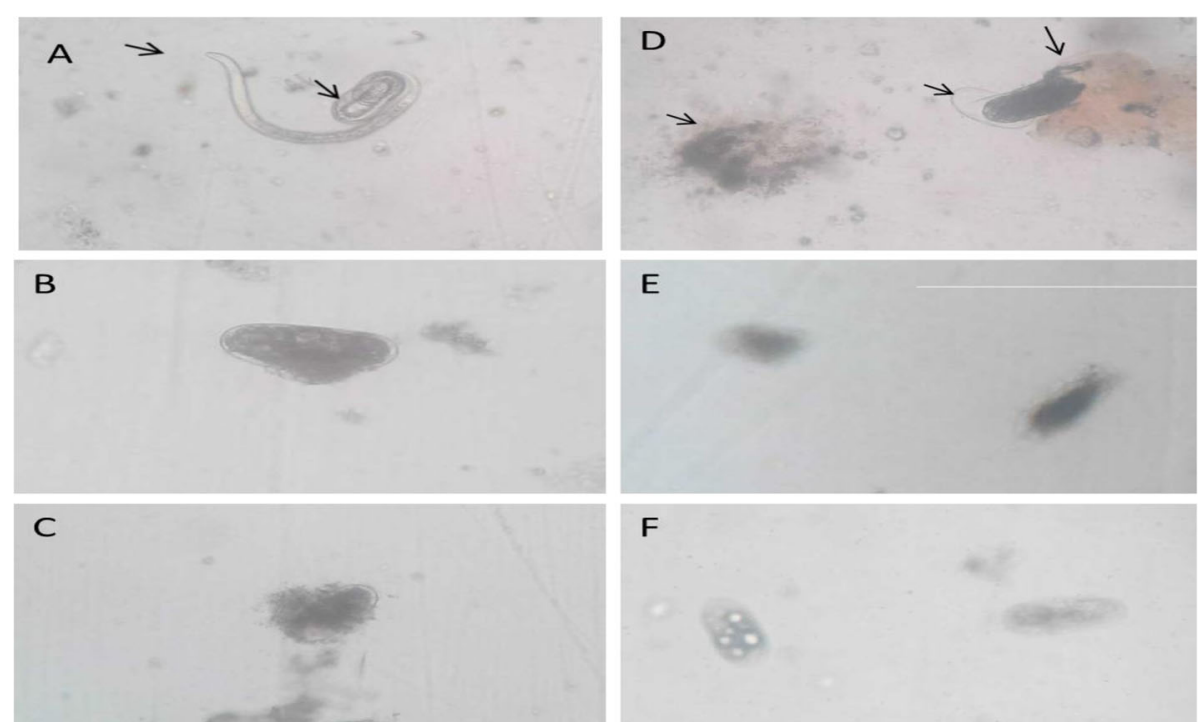

$\mathrm{F}$

Fig. 2 Hatching is observed in the water control; normal juvenile and normal egg (a, arrows). Abnormal development stages are occurred: deforming of eggshell occurred (b, $\mathbf{c}, \mathbf{e}$ ); some eggshells appeared to be destroyed and abnormal hatching (d, arrows). Arrow reveals some eggs 
Table 3 Nematicidal activity of culture filtrates of bacterial strains on Meloidogyne incognita juvenile mortality after $48 \mathrm{~h}$

\begin{tabular}{ll}
\hline Bacterial isolates & $\%$ Mortality* \\
\hline Control (water only) & $0.00 \mathrm{e}$ \\
Pseudomonas aeruginosa CH7GES & $84.89 \mathrm{~d}$ \\
Paenibacillus polymyxa CH6GES & $100.00 \mathrm{a}$ \\
Lysinibacillus sphaericus CH4GES & $92.00 \mathrm{c}$ \\
Bacillus cereus CH4GES & $94.50 \mathrm{bc}$ \\
Bacillus subtilis SGES & $97.24 \mathrm{ab}$ \\
Achromobacter xylosoxidans 19GES & $93.00 \mathrm{c}$
\end{tabular}

*Means followed by the same letter(s) are not significantly different according to Duncan's multiple range test. Data are averages of five replicates

secretion of proteinase and glycoproteinase (Ali et al. 2002). The alkaline protease, BLG4, produced by Bacillus laterosporus reduced about $57 \%$ of nematode activity (Tian et al. 2007). Our results showed that all the strains secreted high levels of chitinase, chitosanase, and protease. However, $P$. aeruginosa exhibited the highest protease activity, $100 \%$. On the other hand, chitosanase produced by the isolated strains exhibited a great ability for chitin degradation, which contributes for suppression of plant pathogenic nematodes.

Prevention of egg hatching by rhizobacteria is one of the most studied mechanisms against the parasite nematodes. Reduction in egg hatching may arise due to the stimulation of plant defense systems by production of plant chitinase and proteases (Seenivasan et al. 2012). Chitinases can disrupt the formation of chitin layers in nematode eggs and prevent egg hatching (Baker 1968). The most affected stages of plant-parasitic nematodes are the egg and the second-stage juvenile. To manage with biological control, these two stages of the plantparasitic nematodes should be controlled, so that the life cycle of nematodes could be interrupted, resulting in a reduction of nematode populations (Xiang et al. 2018). When come in contact with the parasite nematodes, microorganisms release lytic enzymes for effective degradation of egg shell, suppression of egg hatching, and/or inhibition of nematode activity (Xiang et al. 2018).

Numerous studies on plant-growth-promoting rhizobacteria are reported, including both Gram-negative and Gram-positive strains. Gram-negative bacteria, such as Pseudomonads, Burkholderia, Arthrobacter, Achromobacter, and Rhizobium spp., are reported (Antoun 2013; Sidhu 2018; Sohrabi et al. 2018). Gram-positive bacteria such as Brevibacterium, Corynebacterium, Micrococcus, Bacillus, Paenibacillus, and Sarcina are also reported (Lee and Kim 2016; Rika et al. 2017; Sohrabi et al. 2018; Xiang et al. 2018). However, in this study, the six bacterial strains identified as Bacillus, Paenibacillus, and Lysinibacillus (Grampositive bacteria) and Pseudomonas and Achromobacter (Gram-negative bacteria) may indicate the predominance of such genera in the soil as PGPR and could be good factors for suppressing the population density of Meloidogyne spp. The strains studied in the present work may be promising biocontrol agents as PGPR for the future nematode management strategies. The synergistic action of such microorganisms on plant growth and nutrition is of great importance. Results of this study have demonstrated that PGPR can help as an alternative tools and candidates for use in biological control of $M$. incognita to avoid the consumption of nematicides and help for developing more safe sustainable agriculture.

\section{Conclusion}

Rhizobacteria can colonize the plant roots and secrete extracellular enzymes that stimulate plant growth against pathogens, including the root-knot parasite nematodes. The present study revealed that production of chitinase, chitosanase, and protease by Pseudomonas aeruginosa, Paenibacillus polymyxa, Lysinibacillus sphaericus, Bacillus cereus, Bacillus subtilis, and Achromobacter xylosoxidans has effectively suppressed $M$. incognita juveniles, inhibited egg hatching, and reduced nematode growth and activity. Paenibacillus polymyxa and Bacillus subtilis are the most effective strains. Percentage of juvenile mortality reached $100 \%$ and $97 \%$ for Paenibacillus polymyxa and Bacillus subtilis, respectively, whereas egg hatching inhibition recorded $77 \%$ and $78 \%$ for Paenibacillus polymyxa and Bacillus subtilis, respectively. Therefore, microorganisms produce such extracellular enzymes could be used as promising biocontrol agents for future nematode management strategies and provide an alternative approach to nematicides.

\section{Acknowledgements}

This research was done in the laboratories of National Research Centre.

\section{Authors' contributions}

All authors share in every step of this work, and all of them contribute in writing the manuscript. All authors read and approved the final manuscript.

\section{Authors' information}

Dr. Gagiea Mohamed Soliman is a researcher at the National Research Centre, Dokki, Giza, plant pathology Department; Agricultural and Biological Division, Prof. Dr. Hoda Hussein Ameen is a professor at the National Research Centre, Dokki, Giza, plant pathology Department; Agricultural and Biological Division. Prof. Dr. Shadia Mohamed Abdel-Aziz is a professor at the National Research Centre, Dokki, Giza, microbial chemistry Department; genetic engineering and biotechnology Division. Dr. Ghada Mostafa El Sayed is a researcher at the National Research Centre, Dokki, Giza, Microbial genetics Department; genetic engineering and biotechnology Division.

\section{Funding}

This work was supported by chemicals present in National Research Centre through labs.

\section{Availability of data and materials}

The datasets generated during and/or analyzed during the current study are included in this published.

Ethics approval and consent to participate Not applicable. 


\section{Consent for publication}

Not applicable.

\section{Competing interests}

The authors declare that they have no competing interests.

\section{Author details}

${ }^{1}$ Agricultural and Biological Division, Department of Plant Pathology, National Research Centre, Dokki, Giza, Egypt. ${ }^{2}$ Genetic Engineering and Biotechnology Division, Microbial Genetic Department, National Research Centre, Giza, Egypt.

Received: 20 June 2019 Accepted: 23 September 2019

Published online: 04 December 2019

\section{References}

Abbot WS (1925) A method for computing the effectiveness of insecticides. J Econ Ent 18:265-267

Abdel-Aziz SM, Moustafa Y, Mouafi F (2008) Partial purification and some properties of the chitosanases produced by Bacillus alvei NRC-14. J Appl Sci Res 4:1285-1290

Abdel-Salam M, Ameen H, Gaziea MD, Elkelany U, Asar A (2018) Improving the nematicidal potential of Bacillus amyloliquefaciens and Lysinibacillus sphaericus against the root-knot nematode Meloidogyne incognita using protoplast fusion technique. Egyptian J Biol Pest Contr 28:31-36

Ali N, Siddiqui I, Shaukat S, Zaki M (2002) Nematicidal activity of some strains of Pseudomonas spp. Soil Biol Biochem 34:1051-1058

Antoun H (2013) Plant-growth-promoting rhizobacteria. In: Maloy S, Hughes K (eds) Brenner's Encyclopedia of Genetics. Academic Press, San Diego, pp 353-355 https://doi.org/10.1016/B978-0-12-374984-0.01169-4

Ashoub AH, Amara MT (2010) Biocontrol activity of some bacterial genera against root-knot nematode, Meloidogyne incognita. J Amr Sci 6:321-328

Atlas RM (1995) The handbook of microbiological media for the examination of food. CRC Press, Boca Raton, p. 197. Biology 120:487-492

Baker R (1968) Mechanisms of biological control of soil- borne pathogens. Ann Rev Phytopathol 6:263-294

Batool H, Fatima N, Hira K, Sultana V, Ara J, Ehteshamul-Haque S (2013) Role of fluorescent Pseudomonas associated with root nodules of soybean in suppressing the root rotting fungi and root knot nematode of soybean in soil amended with seeds of Vernonia antihelmenthica. Intr J Biol Res 1:73-79

Bird A, McClure M (1976) The tylenchid (nematode) egg shell: structure, composition and permeability. Paracitology 72:19-28

Cetintas R, Kusek M, Ameen Fateh S (2018) Effect of some plant growthpromoting rhizobacteria strains on root-knot nematode, Meloidogyne incognita, on tomatoes. Egyptian Biol Pest Contr 28:7-11

Duncan DB (1955) Multiple range and multiple F tests. Biometrics 11:1-42

El-Alfy A, Schlenk D (2002) Effect of 17\{beta\}-estradiol and testosterone on the expression of flavin-containing mono oxygenase and the toxicity of aldicarbto Japanese Medaka Oryziaslatipes. Toxicol Sci 68:381-388

El-sayed GM, Abo-Serieh NA, Ibrahim S, AbdEl-Razik A, Hammad M, Hafez F (2018) Identification of gene encoding organophosphorus hydrolase (OPH) enzyme in potent organophosphates-degrading bacterial isolates. J Env Sci Technol 11:175-189

Fenton D, Eveleigh D (1981) Purification and mode of action of a chitosanase from Pencillium islandium. J Gen Microbiol 126:151-165

Gheysen G, Mitchum M (2018) Phytoparasitic nematode control of plant hormone pathways. Plant Physiology. https://doi.org/10.1104/pp.18.01067

Glick B (2012) Plant growth-promoting bacteria: mechanisms and applications. Scientifica 2012:1-15

Gupta G, Parihar S, Ahirwar N, Snehi S, Singh V (2015) Plant growth promoting rhizobacteria (PGPR): current and future prospects for development of sustainable agriculture. J Microbiol Biochem Technol 7:096-102

Huang X, Tian B, Niu Q, Yang J, Zhang L, Zhang K (2005) An extracellular protease from Brevibacillus laterosporus G4 without parasporalcrystal can serve as a pathogenic factor in infection of nematodes. Res Microbiol 156: 719-727

Hussey R, Barker K (1973) A comparison of methods of collecting inocula of Meloidogyne spp. including a new technique. Plant Disease Report 57:10251028
Jung W, Jung S, An K, Jin Y, Park R, Kim F, Shon B, Kim T (2002) Effect of chitinase-producing Paenibacillus illinoisis KJA-424 on egg hatching of rootknot nematode (Meloidogyne incognita). J Microbiol Biotechnol 12:865-871

Lee Y, Kim K (2016) Antagonistic potential of Bacillus pumilus L1 against root-knot nematode, Meloidogyne arenaria. J Phytopathol 164:29-39

Lee $Y$, Nguyen X, Naing K, Park Y, Kim K (2015) Role of lytic enzymes secreted by Lysobacter capsici YS1215 in the control of root-knot nematode of tomato plants. Ind J Microbiol 55:74-80

Mercer C, Greenwood R, Grant J (1992) Effect of plant and microbial chitinase on the eggs and juveniles of Meloidogyne hapla Chitwood (Nematoda: Tylenchida). Nematologica 38:227-236

Moens M, Perry R (2009) Meloidogyne species: a diverse group of novel and important plant parasites. In: Perry RN, Moens M, Starr JL (eds) Root-knot nemadodes. CABI Publishing, Wallingford, pp 1-17

Monreal J, Reese E (1969) The chitinase from Serratia marcescens. Canadian J Microbiol 15:689-696

Niu Q, Huang X, Tian B, Yang J, Liu J, Zhang L, Zhang K (2006) Bacillus sp. B16 kills nematodes with a serine protease identified as apathogenic factor. Appl Microbiol Biotechnol 69:722-730

Priyank H, Chinnannan K, Kadirvelu K (2018) Plant growth promoting rhizobacteria (PGPR): a potential alternative tool for Nematodes biocontrol. Biocatal Agr Biotechnol 17:119-128

Rika A, Nyoman P, Tati S (2017) Role of indigenous Rhizosphere bacteria in suppressing root-knot nematode and improve plant growth tomato. Plant Pathol J 16:25-32

Seenivasan N, David P, Vivekanandan P, Samiyappan R (2012) Biological control of rice root-knot nematode, Meloidogyne graminicola through mixture of Pseudomonas fluorescens strains. Biocont Sci Technol 22:611-632

Sidhu H (2018) Potential of plant growth-promoting Rhizobacteria in the management of nematodes: a review. J Entomol Zoology Studies 6:15361545

Smant G, Helder J, Goverse A (2018) Parallel adaptations and common host cell responses enabling feeding of obligate and facultative plant-parasitic nematodes. Plant J 93:686-702

Sohrabi F, Sheikholeslami M, Heydari R, Rezaee S, Sharifi R (2018) Evaluation of four rhizobacteria on tomato growth and suppression of root-knot nematode, Meloidogyne javanica under greenhouse conditions, a pilot study. Egyptian J Biol Pest Contr 28:56-60

Somogyi M (1952) Estimation of sugars by colorimetric method. J Biol Chem 200: 245-254

Spiegel Y, Cohn E, Galper S, Sharon E, Chet I (1991) Evaluation of a newly isolated bacterium, Pseudomonas chitinolytica sp. nov., for controlling the root-knot nematode Meloidogyne javanica. Biocontr Sci Technol 1:115-125

Tian B, Yang J, Lian L, Chunian W, Li N, Zhang K (2007) Role of an extracellular neutral protease in infection against nematodes by Brevibacillus laterosporus strain G4. Appl Microbiol Biotechnol 74:372-380

Wharton D (1980) Nematode eggshells. Parasitology 81:447-463

Xiang N, Kathy S, Donald A (2018) Biological control potential of plant growthpromoting rhizobacteria suppression of Meloidogyne incognita on cotton and Heterodera glycines on soybean: a review. J Phytopathol 166:449-458

\section{Publisher's Note}

Springer Nature remains neutral with regard to jurisdictional claims in published maps and institutional affiliations. 